\title{
The Effect of Copayments for Prescriptions on Adherence to Prescription Medicines in Publicly Insured Populations; A Systematic Review and Meta-Analysis
}

\author{
Sarah-Jo Sinnott ${ }^{1 *}$, Claire Buckley ${ }^{2}$, David O'Riordan ${ }^{1}$, Colin Bradley ${ }^{2}$, Helen Whelton ${ }^{3}$ \\ 1 Department of Epidemiology and Public Health, University College Cork, Cork, Ireland, 2 Department of General Practice, University College Cork, Cork, Ireland, 3 Oral \\ Health Services Research Centre, University College Cork Dental School, Wilton, Cork, Ireland
}

\begin{abstract}
Introduction: Copayments are intended to decrease third party expenditure on pharmaceuticals, particularly those regarded as less essential. However, copayments are associated with decreased use of all medicines. Publicly insured populations encompass some vulnerable patient groups such as older individuals and low income groups, who may be especially susceptible to medication non-adherence when required to pay. Non-adherence has potential consequences of increased morbidity and costs elsewhere in the system.
\end{abstract}

Objective: To quantify the risk of non-adherence to prescribed medicines in publicly insured populations exposed to copayments.

Methods: The population of interest consisted of cohorts who received public health insurance. The intervention was the introduction of, or an increase, in copayment. The outcome was non-adherence to medications, evaluated using objective measures. Eight electronic databases and the grey literature were systematically searched for relevant articles, along with hand searches of references in review articles and the included studies. Studies were quality appraised using modified EPOC and EHPPH checklists. A random effects model was used to generate the meta-analysis in RevMan v5.1. Statistical heterogeneity was assessed using the $\mathrm{I}^{2}$ test; $\mathrm{p}>0.1$ indicated a lack of heterogeneity.

Results: Seven out of 41 studies met the inclusion criteria. Five studies contributed more than 1 result to the meta-analysis. The meta-analysis included 199, 996 people overall; 74, 236 people in the copayment group and 125,760 people in the noncopayment group. Average age was $71.75 y$ years. In the copayment group, (verses the non-copayment group), the odds ratio for non-adherence was $1.11(95 \% \mathrm{Cl} 1.09-1.14 ; \mathrm{P}=<0.00001)$. An acceptable level of heterogeneity at $I^{2}=7 \%,(p=0.37)$ was observed.

Conclusion: This meta-analysis showed an $11 \%$ increased odds of non-adherence to medicines in publicly insured populations where copayments for medicines are necessary. Policy-makers should be wary of potential negative clinical outcomes resulting from non-adherence, and also possible knock-on economic repercussions.

Citation: Sinnott S-J, Buckley C, O'Riordan D, Bradley C, Whelton H (2013) The Effect of Copayments for Prescriptions on Adherence to Prescription Medicines in Publicly Insured Populations; A Systematic Review and Meta-Analysis. PLoS ONE 8(5): e64914. doi:10.1371/journal.pone.0064914

Editor: Maarten Postma, Groningen Research Institute of Pharmacy, United States of America

Received September 20, 2012; Accepted April 21, 2013; Published May 28, 2013

Copyright: ( $) 2013$ Sinnott et al. This is an open-access article distributed under the terms of the Creative Commons Attribution License, which permits unrestricted use, distribution, and reproduction in any medium, provided the original author and source are credited.

Funding: This work was funded by the Health Research Board in Ireland under Grant No. PHD/2007/16. (http://www.hrb.ie/). The funders had no role in study design, data collection and analysis, decision to publish, or preparation of the manuscript.

Competing Interests: The authors have declared that no competing interests exist.

* E-mail: s.sinnott@ucc.ie

\section{Introduction}

In the last decade spending on pharmaceuticals in OECD countries has risen by $50 \%$ [1]. This has led to increased financial pressures in health systems and many countries have attempted to scale back public expenditure on pharmaceuticals; the US, Canada, Australia, Ireland and South Korea have introduced copayment policies to offset growing drug bills [2-7]. A copayment is a fixed fee for a prescription. In theory, copayments are intended to reduce drug expenditure by reducing moral hazard associated with medicines supplied at reduced or zero cost. That is, copayments dis-incentivise the collection of medicines that patients do not consume at home or which have no role in improving health - thus reducing waste [8]. A further function of copayments is to generate revenue to offset drug budget costs. The success of copayment policies, however, depends on the ability of patients to make rational choices about which medications they should or should not take [9-14]. Copayments may be disadvantageous if they cause a decrease in use of medications that are beneficial to health.

The impact of copayment policies in different countries has been assessed in various ways, with significant differences in populations studied, methodologies employed and outcome measures described.

Vulnerable populations are those who have increased sensitivity to adverse health outcomes and typically include older people and 
those on low incomes [15]. Patient groups such as these are commonly covered by public insurance schemes such as Medicaid and Medicare in America, or the General Medical Services scheme in Ireland. Therefore, publicly insured populations may provide a proxy for identifying vulnerable populations.

Assessing the effects of copayments on adherence to prescribed medications in specific populations may offer practical insights, rather than studying general populations; where effect sizes may be diluted [16]. Previous reviews have suggested that patients with low income and chronic disease are particularly susceptible to the unfavourable effects of copayments [17] and that older patients reduce their use of medications in the presence of copayments [16]. Contrary to this, another review [18] stated that poorer and older people may be less sensitive to prescription fees than other reviews had previously reported [16,19]. A reason for this contrast may be differing included studies in reviews, with associated differences in heterogeneity amongst interventions, outcomes and study designs. A review carried out by Rice et al [20] showed that copayments are associated with a decline in health status of older patient groups, with two notable exceptions; those with serious health conditions and those on lower incomes who receive a "financial cushion" around copayments. This evidence, though, is limited by the methodological shortcomings of included studies, including cross-sectional and self-reported data. Furthermore, the outcome of interest in included studies varied and contained patient expenditure, health outcomes and drug utilization.

"Utilization" is an umbrella term which includes the supply, prescription, and use of medicines in a society, with attention to the resulting medical, social, and economic consequences [21]. A more specific outcome than utilization is adherence, which is a component of utilization and refers specifically to "the extent to which patients take their medicines as prescribed" [22]. Reviews in the past have focused on utilization; however, the effect of copayments on adherence is increasingly being researched. It is generally accepted that reduced adherence, which may occur in response to a copayment, leads to poorer health outcomes and increased costs for a health service through hospital admissions and hospital care [23-29]. Furthermore, improved adherence can lead to savings in health expenditures [30,31].

One review has focused on the effects of patient cost sharing on adherence to medicines in a general population [32]. This review and other similar reviews which studied utilization as the main outcome, have quantified the effects of copayments on utilization/ adherence by estimating price elasticities of demand [16,18,33,34]. Price elasticites of demand indicate how responsive demand is to price. Variable elasticities are noted across these reviews, ranging from $2 \%$ to $8 \%$ in a general population. Not all reviews categorized their findings by specific population subgroups $[32,33]$ and none use a homogenous outcome measure. Due to the heterogeneity of included studies in these reviews, it may be possible that summary elasticities do not reflect the true picture, given that it may not have been appropriate to combine individual study effects. Despite numerical differences in elasticities, the direction of results is agreed upon by a Cochrane review in the broad area of cost-sharing, which used the literature published up until 2007. This review echoes the general findings of other reviews; a decreased use of all medicines albeit with a greater decrease in non-essential medicines [35]. An essential medicine is one which is said to proffer health benefits in disease and prolong life, while a non-essential drug is useful in alleviating symptoms only.

Because of inconsistencies in previous reviews and the lack of a meaningful quantitative summary effect of copayments on adherence; this review aimed to consider and quantitatively summarise comparative studies which used an objective measure of adherence. Publicly insured populations typically comprise older and low income individuals, thus the effect in this population was sought as a proxy for identifying vulnerable populations. To date, no review has focused on publicly insured populations. It was hoped that objective measures of adherence, namely Proportion of Days Covered (PDC) and the ReComp Algorithm [36-40] would reduce the heterogeneity of evidence examined. Thus, the question this review seeks to answer is "How do copayments affect adherence to prescribed medications in publicly insured populations?"

\section{Methods}

A recent Cochrane review [35] informed the selection of search terms for this review. However, as the Cochrane review focused on utilisation, some modifications were made to encompass terms that would capture studies examining adherence. Study type filters were amended to include cohort studies (Table 1). Eight databases were searched including; PubMed, Medline(Ovid), Cinahl, EMBASE, EconLit, SCOPUS, Web of Knowledge and the Cochrane Library. The grey literature was also searched through the WHO, OECD and SIGLE. The references of eligible published studies were hand-searched, as were the references of previously published systematic reviews [18,32-35]. There were no language restrictions on searches and the date range extended from 1946 to 2012. Searches were carried out between November 2011 and December 2011. Searches were updated in September 2012. For a study to be eligible for inclusion in the review the following criteria were required: First, the participants received healthcare from a public insurance scheme. The comparator group was the same population/similar population who either didn't pay copayments or experienced no increase in copayment. Second, the intervention was copayment; either an increase in an existing copayment or the introduction of a copayment. Other types of cost-sharing, for example co-insurance, were excluded. Third, the outcome measure was non-adherence. Four commonly used objective measures of adherence were included in search terms; Proportion of Days Covered (PDC), Medication Possession Ratio (MPR), Daily Defined Dose (DDD) and the ReComp algorithm $[36,37,40]$. Although the DDD is generally a measure of utilisation, it was included in this search as a conservative approach to capturing appropriate studies as some studies reporting DDDs may have included indications of adherence. Non-adherence is classified as any percentage of adherence $<80 \%$, an arbitrary but accepted cut-off [36,41]. Next, types of studies included were randomised controlled trials, controlled before and after studies, interrupted time series designs, repeated measures designs, and cohort designs. The types of studies involved were drawn from, and built upon, the study designs used by the Cochrane Effective Practice and Organisation of Care (EPOC) Review group. Lastly, only adjusted estimates of adherence were included in the meta-analysis [42].

Searches were carried out by the main reviewer (SJS). Exclusion of titles and abstracts were confirmed with DOR and CB. Authors of any relevant abstracts which did not have a retrievable whole paper were contacted via email for follow up on subsequent publishing of whole papers. Data extraction was carried by SJS and duplicated by DOR and $\mathrm{CB}$ using standardised data extraction forms. Data extracted included general demographic information, copayment value, copayment status, outcome measure used, follow up time and adjusted odds ratios. Disagreements were resolved by discussion and where necessary involved other authors $(\mathrm{CBr}$ and $\mathrm{HW})$. When required, authors were contacted 
Table 1. Search terms used in searches of electronic databases.

\begin{tabular}{|c|c|c|}
\hline Intervention & Outcome & Study Filters \\
\hline $\begin{array}{l}\text { Cost sharing } \\
\text { Deductibles and coinsurance* } \\
\text { Capitation fee } \\
\text { Fees, pharmaceutical } \\
\text { Fees and charges }\end{array}$ & $\begin{array}{l}\text { Medication adherence } \\
\text { Patient compliance } \\
\text { Pharmaceutical preparation* } \\
\text { Prescription drugs } \\
\text { Drug costs } \\
\text { Drug Utilization* } \\
\text { Drug prescriptions }\end{array}$ & $\begin{array}{l}\text { Randomized controlled trial (publication type) } \\
\text { Controlled clinical trial (publication type) } \\
\text { Intervention studies } \\
\text { Evaluation studies (publication type) } \\
\text { Comparative studies (publication type) } \\
\text { Retrospective cohort }\end{array}$ \\
\hline \multirow[t]{2}{*}{$\begin{array}{l}\text { Textwords } \\
\text { Cost shar* } \\
\text { Co-payment } \\
\text { Co-pay* } \\
\text { Copayment } \\
\text { Copay* } \\
\text { Co payment } \\
\text { Co pay* }\end{array}$} & $\begin{array}{l}\text { Textwords } \\
\text { Medication possession ratio } \\
\text { Defined Daily Dose } \\
\text { Proportion Days Covered } \\
\text { ReCOMP algorithm }\end{array}$ & $\begin{array}{l}\text { Textwords } \\
\text { Experiment } \\
\text { Time series } \\
\text { Interrupted time series } \\
\text { (Pre test or pretest or (posttest or post test) } \\
\text { Impact } \\
\text { Intervention* } \\
\text { Effect* } \\
\text { Evaluat* }\end{array}$ \\
\hline & & $\begin{array}{l}\frac{\text { NOT }}{\text { Letter }} \\
\text { Comment } \\
\text { Editorial }\end{array}$ \\
\hline
\end{tabular}

These search terms or variants were used in all databases

doi:10.1371/journal.pone.0064914.t001

by email for data. If no response was gained, a reminder email was sent. The study was excluded if there was no response. Controlled before and after studies and interrupted time series designs were assessed for quality and risk of bias using a modified version of the EPOC Data Collection Checklist and Quality Criteria for CBA and ITS [43]. Using this tool, studies could be rated as strong, moderate, weak or fatally flawed. A study was rated as "weak" if two or more criteria were unmet. Cohort studies were assessed for quality and risk of bias using the Effective Public Health Practice Project component rating scale [44]. Using this tool, studies could be given strong, moderate or weak status. A study was rated as "weak" if it was given two weak ratings across the constituent criteria. Both tools for quality included an assessment of confounding.

RevMan version 5.1 [45] was used to carry out the metaanalysis. The $\log (\mathrm{OR})$ and corresponding standard error were inputted. The summary effect measure calculated was the odds ratio and its corresponding $95 \%$ confidence interval. Statistical heterogeneity was assessed using the $\mathrm{I}^{2}$ test for heterogeneity in RevMan. A conservative value of $\mathrm{p}>0.1$ indicated a lack of heterogeneity. A random effects model was used. The outcomes of all PDC and ReCOMP studies were combined in one metaanalysis because they both measure the same outcome; adherence. A sensitivity analysis was performed to ensure suitability of combination - the combination of the two measures did not distort the conclusion. Sensitivity analyses for publication types and demographics (gender) were also run, no differences in conclusion were observed (Figures S1, S2, S3, S4). The medicines that occurred in the included studies are medicines used in chronic disease and have been referred to as being essential [35]. Therefore, a degree of homogeneity across these medicines permits combination in one meta-analysis.

Publication bias was assessed using visual inspection of a funnel plot generated in RevMan. Formal tests of asymmetry were not appropriate due to similar numbers involved in studies and the lack of more than ten studies in the meta-analysis. The small study effect was investigated by sensitivity analysis and fixed model random effects model comparisons.

\section{Results}

\section{Search results and study characteristics}

From the initial searches, 6 out of 22 studies met the inclusion criteria for meta-analysis [46-51]. An additional study [52] out of 19 studies was added from a search update in September 2012 to give 7 included studies overall. A Prisma flowchart (Figure 1) demonstrates how the search results were obtained and sequentially ruled out from final inclusion. Table 2 gives details of the 7 studies included in the meta-analysis. All studies were carried out in the US, despite no geographical limitations in search. Four studies focused on Medicare insurance plans [46,47,51,52] and 3 studies analysed copayment increases in Veteran Affairs [48-50]. The average age of patients included in studies was 71.75years (range 64.8yrs to 85+yrs). Gender was evenly distributed between copay and non-copay groups except in Veteran studies which were predominantly male. Five studies [46-48,51,52] examined adherence using the PDC measure and 2 studies [49,50] used the ReComp measure of adherence. Four studies were cohort designs and 3 studies were controlled before and after studies. The metaanalysis includes 7 studies in 16 separate patient/medication groups, because 5 studies analysed adherence to medication groups individually or analysed patient groups at different levels of morbidity [46,49-52]. The value of copayments ranged from $\$ 5$ to $\$ 70$. Details of excluded studies are included in Table S1.

\section{Quality assessment}

Table 3 gives the details of quality assessment of the studies. Included studies were all of weak or weak-moderate strength. Sources of weakness were derived from characteristics imbalances in copayment groups and non-copayment groups, along with poor information given on follow up/attrition.

\section{Publication bias}

Asymmetry was noted in the funnel plot. Asymmetry may be due to a publication bias, that is, authors do not publish studies of no effect, which results in an overestimation of the true effect. However, asymmetry may also be caused by weak methodological 


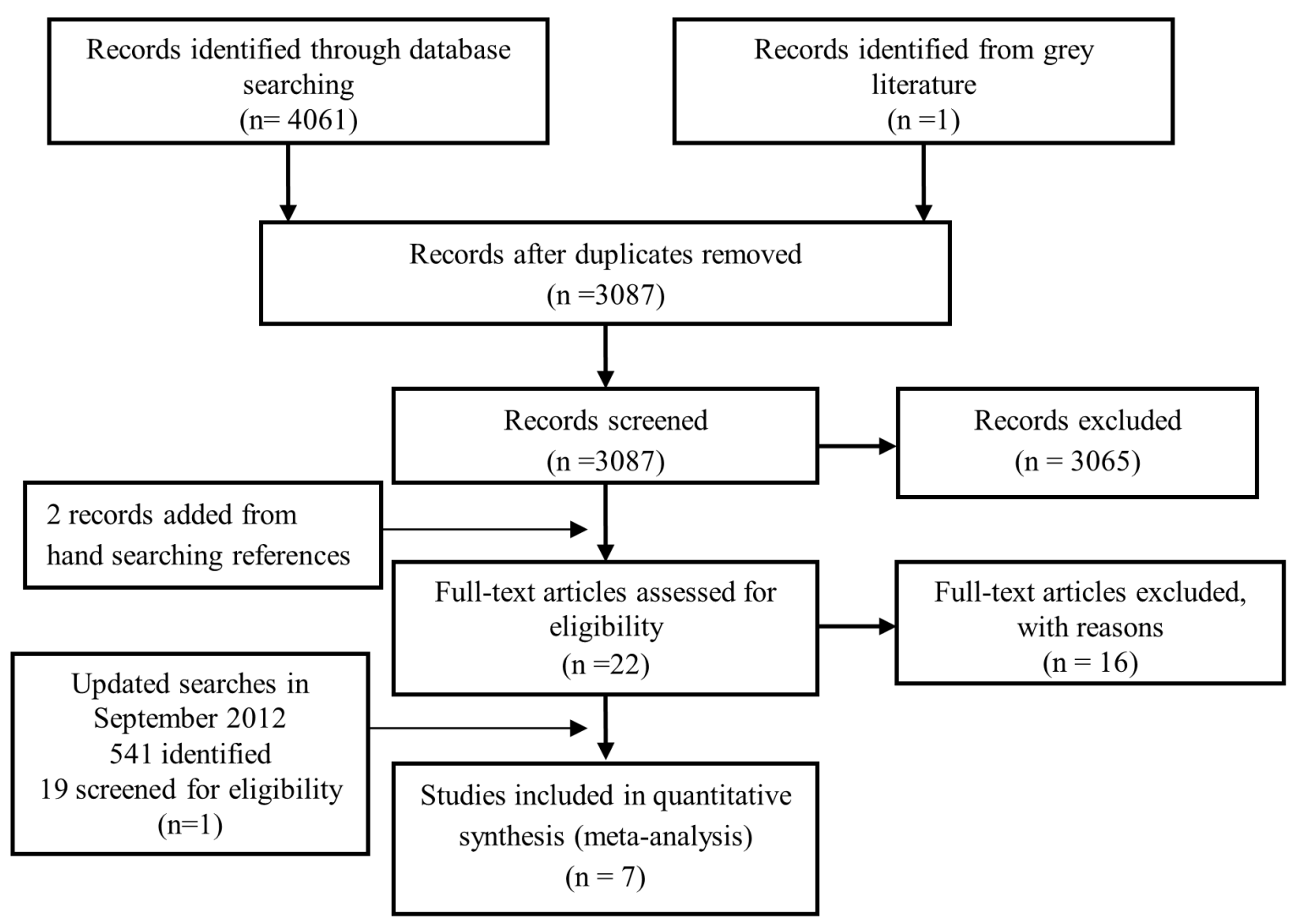

Figure 1. A PRISMA flowchart outlining the procurement of $\mathbf{7}$ included studies. doi:10.1371/journal.pone.0064914.g001

practices in studies. In this meta-analysis all included studies were of weak design. The small study effect was not present.

\section{Non-adherence when exposed to copayment}

The meta-analysis included 199, 996 people overall; 74,236 people in the copayment group and 125, 760 people in the noncopayment group. These numbers may overestimate the true number of individuals because the 7 included studies contributed 16 separate patient groups, and there may have been some overlap. Figure 2 shows the results of the meta-analysis which plots the outcome, non-adherence, as affected by the exposure, requirement to copay for prescription drugs. The summary odds ratio for non-adherence is 1.11 (95\% CI $1.09-1.14 ; \mathrm{P}=<0.00001)$ in the copayment group. Results were consistent across studies; an acceptable level of heterogeneity at $\mathrm{I}^{2}=7 \%,(\mathrm{p}=0.37)$ was observed.

\section{Discussion}

This meta-analysis has found an $11 \%$ increase in odds of nonadherence when publicly insured patients are required to copay for their prescription medicines. This is a pertinent result because the question regarding adherence to medicines in a cost sharing environment was still inconclusively quantitatively answered by prior reviews [18,33-35].

Medication classes that appeared more than once in the metaanalysis included those for hypertension, hyperlipidaemia and diabetes; medicines which are regarded as being essential. This gives this meta-analysis particular relevance; because lack of adherence to these medicines can be important clinically and economically.

While adherence is a surrogate outcome for clinical outcomes, there is a body of literature which allows extrapolation of this finding to give meaningful clinical results. People with diabetes are traditionally poor adherers to chronic medications with reported levels of adherence as low as 50\% [53]. This occurs despite the knowledge that tight glycaemic control results in fewer complications for patients and also has economic benefits [31,54-56]. Similarly, rates of adherence to hypertensive medicines are widely reported to be poor; with rates of adherence at $50 \% 1$ year after starting treatment [57]. Well-controlled hypertension is seen at levels of adherence at over $80 \%$ [58]. Cherry et al [59] showed approximately a double relative risk of myocardial infarction, stroke and angina in non-adherers verses those who have "ideal" adherence to anti-hypertensive medicines. Their research also outlined the economic burden of non-adherence, costing roughly $\$ 8,500 /$ life year gained more than full adherence. It has been found that non-adherence to oral hypoglycaemics, anti-hypertensives and statins in more than 11,000 patients with diabetes was significantly associated with all cause hospitalisations and all cause mortality [60]. These results have financial implications as described by Sokol et al, who demonstrated that adherence to medicines used to treat diabetes and hypercholesteremia reduces expenditure in overall health costs [27]. In hypertensive disease, the same results have been shown by McCombs et al [61]. The result of this meta-analysis shows copayment to be an additional risk factor for non-adherence. Given the already low adherence profiles to these essential drugs and the associated costly 


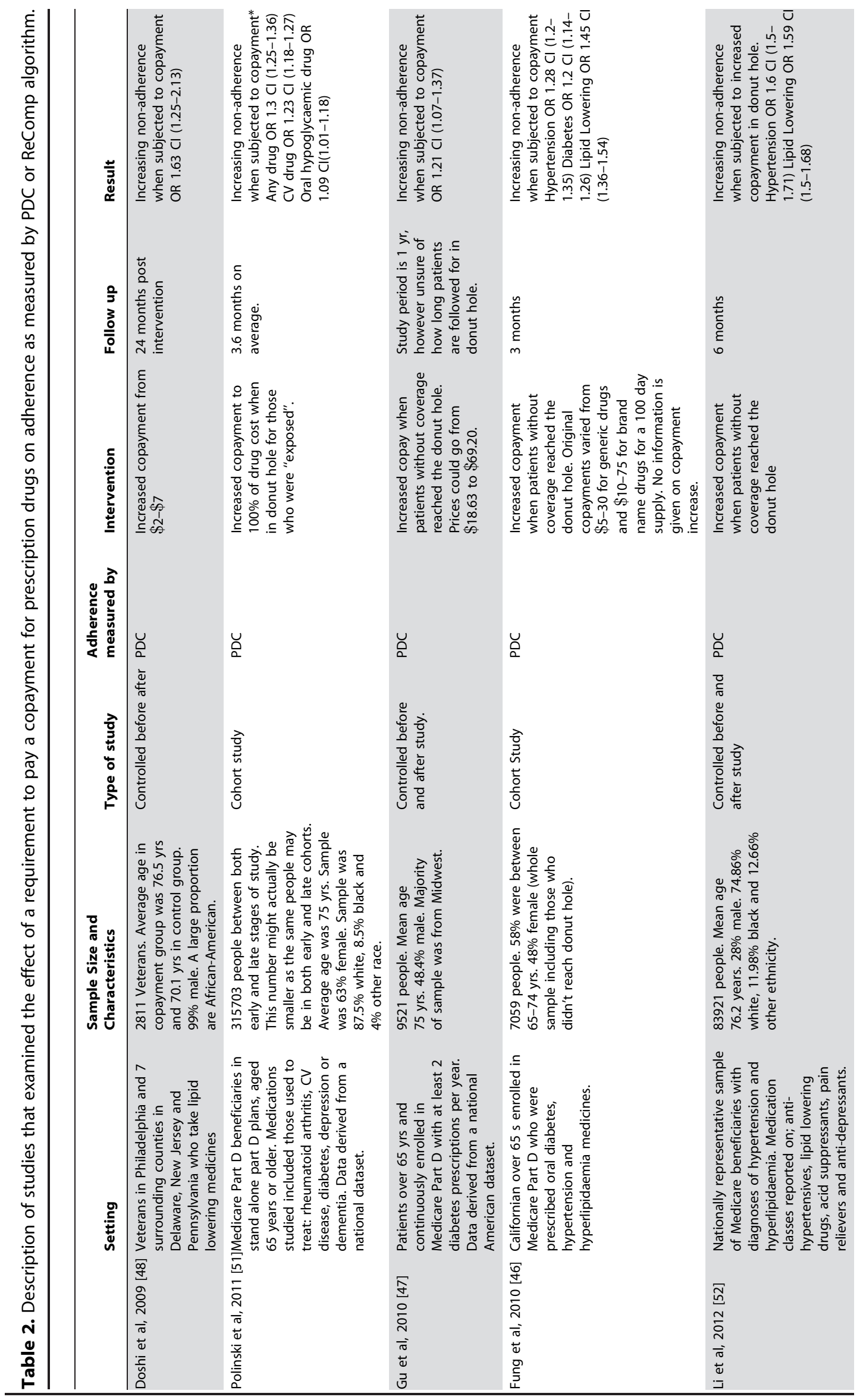




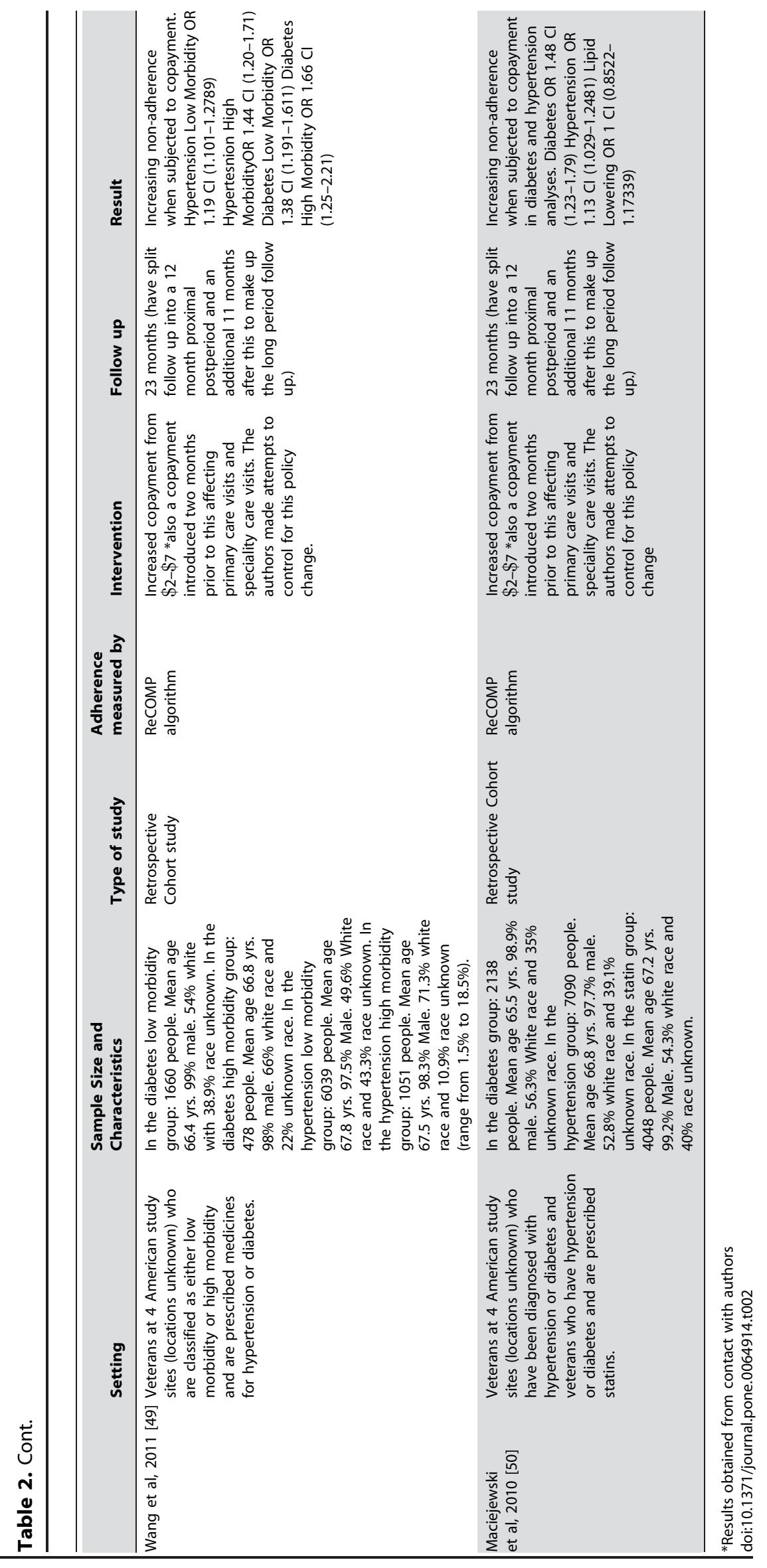




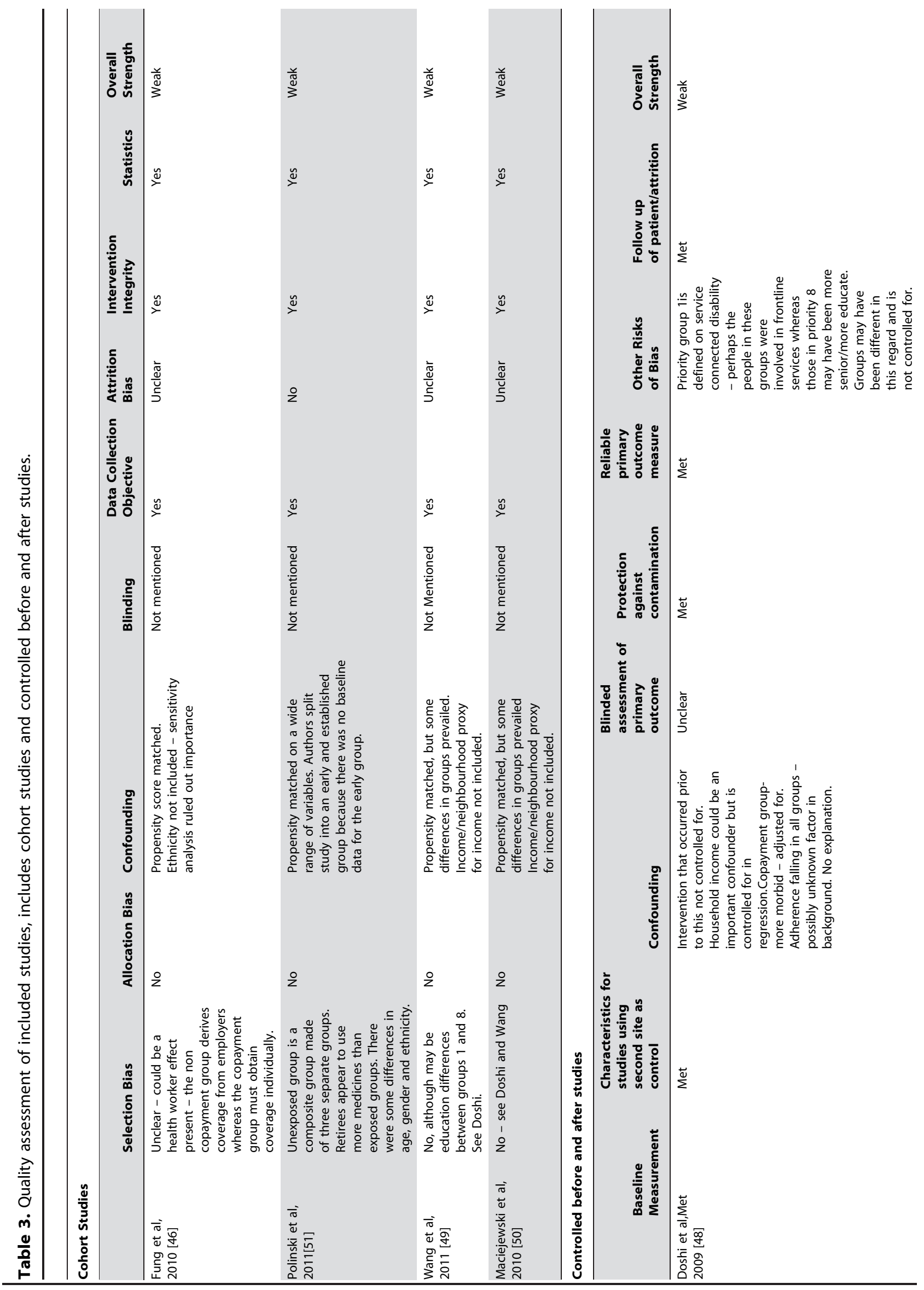




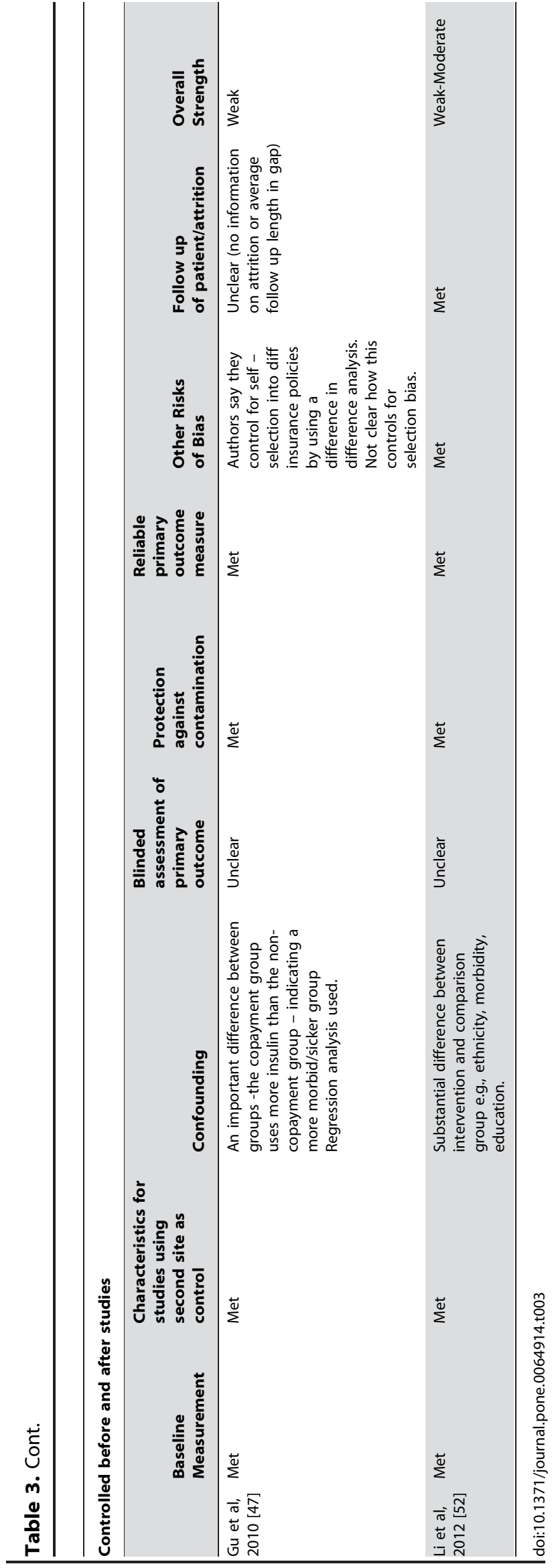

repercussions, an $11 \%$ increased odds of non-adherence to these medicines may be important clinically and economically.

The results of this meta-analysis agree with the qualitative results of reviews that have been published in the broader area of cost-sharing and utilisation of drugs [33-35]. Previous reviews quantified broadly defined utilisation by calculating elasticities $[18,32,34]$. Nevertheless, this is the first review to encompass a meta-analysis and give a numerical summary measure of the odds of non-adherence when individuals are required to copay for medicines. In addition, this review builds upon recent related reviews such as Eaddy et al [32] by focusing solely on publicly insured populations.

Pharmaceutical expenditure is difficult to contain at present due to a global aging population and the increased incidence of morbidity that this is associated with. To compound this, the growth of the pharmaceutical bio-technology industry and the development of biological drugs that are increasingly prescribed will serve to maintain, if not increase, public spending on pharmaceuticals. It is imperative for policy makers and health economists to devise practical and balanced cost sharing policies that do not represent a barrier to cheap, effective medicines which produce health gains at a large population level. Such health gains result in large financial savings by maintaining public health and by decreased health services utilisation $[27,62]$. Simultaneously however, drug expenditure policies must account for moral hazard and attempt to confer upon the patient the notion of cost responsibility. Due to clinical, financial and political influences cost-sharing policies are often difficult to formulate. This metaanalysis will contribute to the body of evidence that should be used as a guide in future decision making.

\section{Limitations}

Despite strict inclusion and exclusion criteria which were developed to obtain studies that would be comparable, some differences in research methodologies persisted. First, follow up times in the included studies varied widely, ranging from 3 months to 2 years. Secondly, this type of research is vulnerable to confounding and not all studies controlled for the same confounders. For example 2 studies attempted to control for an introduced fee for physician care [49,50], whereas another paper experiences the same physician fee, but does not control for this confounder [48]. Thirdly, the included studies were of weak to moderate quality. Given the non-experimental nature of this research this is a problem that is difficult to avoid. Regardless, the quality of included studies should be borne in mind when interpreting the summary effect measure. There are methodological strengths in the included studies such as propensity score matching that attenuate the biased nature of some observational research designs. However propensity score matching can leave residual confounding between groups and cannot account for unknown or immeasurable confounding as a randomised controlled trial only can.

It may be worth noting that qualitative analysis of interrupted time series studies [5] may provide an interesting insight into patient behaviours over a period of time. Analysis of such results would show how adherence fluctuates in the months preceding the policy change, for example, adherence to $\beta$-blockers introduced after a myocardial infarction can fall rapidly even before a copay policy change [5]. However, a meta-analysis of such data would be impractical, thus the method employed in the meta-analysis presented here is a pragmatic way of analysing the key research question.

Next, the studies included in this review were concerned with drugs that act primarily in cardiovascular disease and diabetes. 


\begin{tabular}{|c|c|c|c|c|c|c|c|}
\hline \multirow{2}{*}{$\begin{array}{l}\text { Study or Subgroup } \\
\text { Doshi } 2009 \text {-Lipid Lowering }\end{array}$} & log[Odds Ratio] & \multirow{2}{*}{$\begin{array}{r}\text { SE } \\
0.224\end{array}$} & \multirow{2}{*}{$\begin{array}{r}\text { Weight } \\
0.3 \%\end{array}$} & \multirow{2}{*}{\begin{tabular}{c}
\multicolumn{1}{c}{$\begin{array}{c}\text { Odds Ratio } \\
\text { IV, } \text { Random, } 95 \% \mathrm{CI}\end{array}$} \\
$1.24[0.80,1.92]$
\end{tabular}} & \multicolumn{3}{|c|}{$\begin{array}{c}\text { Odds Ratio } \\
\text { IV, Random, } 95 \% \mathrm{Cl}\end{array}$} \\
\hline & 0.215 & & & & & & \\
\hline Fung 2010 - Diabetes & 0.081 & 0.031 & $12.4 \%$ & $1.08[1.02,1.15]$ & & $\rightarrow$ & \\
\hline Fung 2010 - Hypertension & 0.107 & 0.038 & $8.7 \%$ & $1.11[1.03,1.20]$ & & $\varpi$ & \\
\hline Fung 2010-Lipid Lowering & 0.161 & 0.043 & $6.9 \%$ & $1.17[1.08,1.28]$ & & $\rightarrow-$ & \\
\hline Gu 2010-Diabetes & 0.082 & 0.076 & $2.3 \%$ & $1.09[0.94,1.26]$ & & & \\
\hline Li 2012- Lipid Lowering & 0.201 & 0.046 & $6.1 \%$ & $1.22[1.12,1.34]$ & & & \\
\hline Li 2012 - Hypertension & 0.204 & 0.053 & $4.7 \%$ & $1.23[1.11,1.36]$ & & $\longrightarrow$ & \\
\hline Maciejewski 2010 - Hypertension & 0.055 & 0.055 & $4.4 \%$ & $1.06[0.95,1.18]$ & & 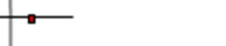 & \\
\hline Maciejewski 2010-Lipid Lowering & 0 & 0.0819 & $2.0 \%$ & $1.00[0.85,1.17]$ & & & \\
\hline Maciejewski 2010-Diabetes & 0.171 & 0.14 & $0.7 \%$ & $1.19[0.90,1.56]$ & & & \\
\hline Polinski 2011- Any Drug & 0.114 & 0.028 & $14.6 \%$ & $1.12[1.06,1.18]$ & & $\rightarrow$ & \\
\hline Polinski 2011 - Cardiovascular & 0.089 & 0.022 & $21.4 \%$ & $1.09[1.05,1.14]$ & & $\rightarrow$ & \\
\hline Polinski 2011 - Hypoglycaemic & 0.037 & 0.043 & $6.9 \%$ & $1.04[0.95,1.13]$ & & 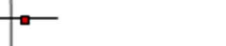 & \\
\hline Wang 2011 - High Mor - Hypertension & 0.158 & 0.13 & $0.8 \%$ & $1.17[0.91,1.51]$ & & & \\
\hline Wang 2011 - Low Mor - Diabetes & 0.14 & 0.107 & $1.2 \%$ & $1.15[0.93,1.42]$ & & & \\
\hline Wang 2011 - Low Mor - Hypertension & 0.075 & 0.045 & $6.4 \%$ & $1.08[0.99,1.18]$ & & 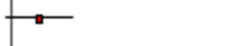 & \\
\hline Wang 2011-High Mor-Diabetes & 0.22 & 0.244 & $0.2 \%$ & $1.25[0.77,2.01]$ & & & \\
\hline Total $(95 \% \mathrm{Cl})$ & & & $100.0 \%$ & $1.11[1.09,1.14]$ & & $\hat{1}$ & \\
\hline \multicolumn{4}{|c|}{ Heterogeneity: $\operatorname{Tau}^{2}=0.00 ; \mathrm{Chi}^{2}=17.23, \mathrm{df}=16(P=0.37) ; \mathrm{I}^{2}=7 \%$} & & $0.5 \quad 0.7$ & 1.5 & 2 \\
\hline \multicolumn{4}{|c|}{ Test for overall effect: $Z=8.88(P<0.00001)$} & \multicolumn{2}{|r|}{ Non copayment group } & Copayment group & \\
\hline
\end{tabular}

Figure 2. Effect of requirement to pay a copayment for prescription drugs on non-adherence in a publicly insured population. doi:10.1371/journal.pone.0064914.g002

Therefore the results of the meta-analysis may not be extrapolated to other disease groups such as cancer or pain. However, given that cardiovascular disease, ischaemic heart disease and diabetes are included in the top ten causes of death in high income countries [63] these results still have high relevancy and a wide generalisabilty. Despite this, external validity may suffer as some studies excluded the poorest members of society due to different coverage status for these people [46,47]. Furthermore, the studies included in this review focus on elderly populations. Therefore, the results may not be applicable to younger vulnerable populations. However, given that elderly populations are the biggest users of pharmaceuticals $[64,65]$, this review still gives pertinent information. Further analysis in younger, low income populations should be undertaken to fill in the information gaps.

There may have been a degree of publication bias present. Efforts were made to overcome this problem in the development of the search strategy which encompassed 8 electronic databases, the grey literature and hand-searching. The potential presence of publication bias should be kept in mind when interpreting the summary effect of this meta-analysis.

Lastly, this meta-analysis was explicit in the intervention analysed i.e., an introduced or increased copayment. Results from this analysis may not be extendable to other cost-sharing policies such as co-insurance, because the effects of different cost-sharing policies are not necessarily always comparable [4]. However, there is no reason why these results cannot be extrapolated in a directional manner for other policies.

\section{Conclusions}

This meta-analysis showed an $11 \%$ increased odds of nonadherence to medicines in publicly insured populations involved in a system where copayments for medicines are required. Reductions in adherence to medications, especially essential medicines, can be detrimental to health status and causes increases in expenditure via hospital admissions. Hence, the results of this meta-analysis should be taken into account at a policy and health systems level to aid in striking a balance between the financial benefits and financial repercussions of cost-sharing policies.

\section{Supporting Information}

Figure S1 Sensitivity analysis for study design; CBA studies.

(TIF)

Figure S2 Sensitivity analysis for study design; Cohort studies.

(TIF)

Figure S3 Sensitivity analysis for gender differences in studies; Studies with mixed genders.

(TIF)

Figure S4 Sensitivity analysis for gender differences in studies; Studies with predominant male distribution. (TIF)

Table S1 Excluded studies and reasons for exclusion. (DOCX) 


\section{Acknowledgments}

SJS would like to Professor John Browne, University College Cork, Ireland who teaches PG7016, a postgraduate module in Systematic Reviews in the Health Sciences. The completion of this course was an invaluable instruction in the science of systematic reviews.

\section{References}

1. OECD (2011) "Pharmaceutical expenditure", in Health at a Glance 2011: OECD Indicators: OECD Publishing.

2. Lee IH, Bloor K, Hewitt C, Maynard A (2012) The effects of new pricing and copayment schemes for pharmaceuticals in South Korea. Health Policy 104: 4049.

3. Hynd A, Roughead EE, Preen DB, Glover J, Bulsara M, et al. (2009) Increased patient co-payments and changes in PBS-subsidised prescription medicines dispensed in Western Australia. Australian \& New Zealand Journal of Public Health 33: 246-252.

4. Schneeweiss S, Patrick AR, Maclure M, Dormuth CR, Glynn RJ (2007) Adherence to statin therapy under drug cost sharing in patients with and without acute myocardial infarction: a population-based natural experiment. Circulation 115: 2128-2135.

5. Schneeweiss S, Patrick AR, Maclure M, Dormuth CR, Glynn RJ (2007) Adherence to beta-blocker therapy under drug cost-sharing in patients with and without acute myocardial infarction. American Journal of Managed Care 13: 445-452.

6. Farley JF (2010) Medicaid prescription cost containment and schizophrenia: a retrospective examination. Medical Care 48: 440-447.

7. Barry M, Usher C, Tilson L (2010) Public drug expenditure in the Republic of Ireland. Expert Review of Pharmacoeconomics and Outcomes Research 10: 239-245.

8. McPake B, Normand C (2008) Health economics: an international perspective 2nd ed. Oxon: Routledge.

9. Reeder CE, Nelson AA (1985) The differential impact of copayment on drug use in a Medicaid population. Inquiry 22: 396-403.

10. Harris BL, Stergachis A, Ried LD (1990) The effect of drug co-payments on utilization and cost of pharmaceuticals in a health maintenance organization. Medical Care 28: 907-917.

11. Brian EW, Gibbens SF (1974) California's Medi-Cal copayment experiment. Medical Care 12: 1-303.

12. Tamblyn R, Laprise R, Hanley JA, Abrahamowicz M, Scott S, et al. (2001) Adverse events associated with prescription drug cost-sharing among poor and elderly persons. JAMA 285: 421-429.

13. McManus P, Donnelly N, Henry D, Hall W, Primrose J, et al. (1996) Prescription drug utilization following patient co-payment changes in Australia. Pharmacoepidemiology and Drug Safety 5: 385-392.

14. Hynd A, Roughead EE, Preen DB, Glover J, Bulsara M, et al. (2008) The impact of co-payment increases on dispensings of government-subsidised medicines in Australia. Pharmacoepidemiology \& Drug Safety 17: 1091-1099.

15. Flaskerud JH, Winslow BJ (1998) Conceptualizing vulnerable populations health-related research. Nursing Research 47: 69-78.

16. Lexchin J, Grootendorst P (2004) Effects of prescription drug user fees on drug and health services use and on health status in vulnerable populations: A systematic review of the evidence. International Journal of Health Services 34: $101-122$.

17. Adams AS, Soumerai SB, Ross-Degnan D (2001) The case for a medicare drug coverage benefit: a critical review of the empirical evidence. Annu Rev Public Health 22: 49-61.

18. Gemmill MC, Thomson S, Mossialos E (2008) What impact do prescription drug charges have on efficiency and equity? Evidence from high-income countries. International Journal for Equity in Health 7.

19. Smith DG, Kirking DM (1992) Impact of consumer fees on drug utilisation. Pharmacoeconomics 2: 335-342.

20. Rice T, Matsuoka KY (2004) The impact of cost-sharing on appropriate utilization and health status: A review of the literature on seniors. Medical Care Research and Review 61: 415-452.

21. World Health Organization (1977) The Selection of Essential Drugs: Report of a WHO Expert Committee. Geneva: World Health Organization. WHO Technical Report Series, No. 615.

22. Osterberg L, Blaschke T (2005) Adherence to medication. N Engl J Med 353: 487-497.

23. Atella V, Peracchi F, Depalo D, Rossetti C (2006) Drug compliance, co-payment and health outcomes: evidence from a panel of Italian patients. Health Economics 15: 875-892.

24. Soumerai S, Thomas JM, Ross-Degnan D, Casteris CS, Bollini P (1994) Effects of limiting Medicaid drug-reimbursement benefits on the use of pychotropic agents and acute mental health services by patients with schizophrenia. New England Journal of Medicine 331.

25. Soumerai SB, Ross-Degnan D, Avorn J, McLaughlin T, Choodnovskiy I (1991) Effects of Medicaid drug-payment limits on admission to hospitals and nursing homes. N Engl J Med 325: 1072-1077.

\section{Author Contributions}

Conceived and designed the experiments: SJS C. Buckley DOR C. Bradley HW. Performed the experiments: SJS C. Buckley DOR. Analyzed the data: SJS. Wrote the paper: SJS. Revising draft for intellectual content and provision of corrections: C. Buckley DOR G. Bradley HW.

26. Tamblyn R, Laprise R, Hanley JA, Abrahamowicz M, Scott S, et al. (2001) Adverse events associated with prescription drug cost-sharing among poor and elderly persons. Journal of the American Medical Association 285: 421-429.

27. Sokol MC, McGuigan KA, Verbrugge RR, Epstein RS (2005) Impact of medication adherence on hospitalization risk and healthcare cost. Medical Care 43: 521-530.

28. Cohen J, Christensen K, Feldman L (2012) Disease management and medication compliance. Population Health Management 15: 20-28.

29. Choudhry NK, Avorn J, Glynn RJ, Antman EM, Schneeweiss S, et al. (2011) Full coverage for preventive medications after myocardial infarction. N Engl J Med 365: 2088-2097.

30. Stuart B, Davidoff A, Lopert R, Shaffer T, Samantha Shoemaker J, et al. (2011) Does medication adherence lower Medicare spending among beneficiaries with diabetes? Health Services Research 46: 1180-1199.

31. Jha AK, Aubert RE, Yao J, Teagarden JR, Epstein RS (2012) Greater Adherence To Diabetes Drugs Is Linked To Less Hospital Use And Could Save Nearly \$5 Billion Annually. Health Affairs 31: 1836-1846.

32. Eaddy MT, Cook CL, O'Day K, Burch SP, Cantrell CR (2012) How patient cost-sharing trends affect adherence and outcomes: a literature review. P T 37 : $45-55$.

33. Gibson TB, Ozminkowski RJ, Goetzel RZ (2005) The effects of prescription drug cost sharing: a review of the evidence. American Journal of Managed Care 11: $730-740$.

34. Goldman DP, Joyce GF, Zheng Y (2007) Prescription drug cost sharing associations with medication and medical utilization and spending and health. Jama-Journal of the American Medical Association 298: 61-69.

35. Austvoll-Dahlgren A, Aaserud M, Vist G, Ramsay C, Oxman AD, et al. (2008) Pharmaceutical policies: Effects of cap and co-payment on rational drug use. Cochrane Database of Systematic Reviews.

36. Andrade SE, Kahler KH, Frech F, Chan KA (2006) Methods for evaluation of medication adherence and persistence using automated databases. Pharmacoepidemiology \& Drug Safety 15: 565-574; discussion 575-567.

37. Karve S, Cleves MA, Helm M, Hudson TJ, West DS, et al. (2009) Prospective validation of eight different adherence measures for use with administrative claims data among patients with schizophrenia. Value in Health 12: 989-995.

38. Karve S, Cleves MA, Helm M, Hudson TJ, West DS, et al. (2009) Good and poor adherence: optimal cut-point for adherence measures using administrative claims data. Current Medical Research \& Opinion 25: 2303-2310.

39. Hess LM, Raebel MA, Conner DA, Malone DC (2006) Measurement of adherence in pharmacy administrative databases: a proposal for standard definitions and preferred measures. Annals of Pharmacotherapy 40: 1280-1288.

40. Bryson CL, Au DH, Young B, McDonell MB, Fihn SD (2007) A refill adherence algorithm for multiple short intervals to estimate refill compliance (ReComp). Medical Care 45: 497-504.

41. Cramer JA, Roy A, Burrell A, Fairchild CJ, Fuldeore MJ, et al. (2008) Medication compliance and persistence: terminology and definitions. Value in Health 11: 44-47.

42. Peters J, Mengersen K (2008) Selective reporting of adjusted estimates in observational epidemiology studies: reasons and implications for meta-analyses. Eval Health Prof 31: 370-389.

43. Effective Practice and Organisation of Care Review Group - Cochrane Data Collection Checklist http://epoc.cochrane.org/sites/epoc.cochrane.org/files/ uploads/datacollectionchecklist.pdf. Last accessed from http://epoc.cochrane. org April 2013.

44. Effective Public Health Practice Project Quality Assessment Tool for Quantitative Studies http://www.ephpp.ca/PDF/Quality\%20Assessment\%20Tool_2010_2. pdf. Last accessed from www.ephpp.ca April, 2013

45. RevMan (2011) Review Manager (RevMan) [Computer program]. Version 5.1. Copenhagen: The Nordic Cochrane Centre, The Cochrane Collaboration, 2011.

46. Fung V, Mangione CM, Huang J, Turk N, Quiter ES, et al. (2010) Falling into the coverage gap: Part D drug costs and adherence for Medicare Advantage prescription drug plan beneficiaries with diabetes. Health Services Research 45: 355-375.

47. Gu Q Zeng F, Patel BV, Tripoli LC (2010) Part D Coverage Gap and Adherence to Diabetes Medications. American Journal of Managed Care 16: 911-918.

48. Doshi JA, Zhu J, Lee BY, Kimmel SE, Volpp KG (2009) Impact of a prescription copayment increase on lipid-lowering medication adherence in veterans. Circulation 119: 390-397.

49. Wang V, Liu CF, Bryson CL, Sharp ND, MacIejewski ML (2011) Does medication adherence following a copayment increase differ by disease burden? Health Services Research 46: 1963-1985. 
50. Maciejewski ML, Bryson CL, Perkins M, Blough DK, Cunningham FE, et al. (2010) Increasing Copayments and Adherence to Diabetes, Hypertension, and Hyperlipidemic Medications. American Journal of Managed Care 16: E20-E34.

51. Polinski JM, Shrank WH, Huskamp HA, Glynn RJ, Liberman JN, et al. (2011) Changes in drug utilization during a gap in insurance coverage: an examination of the medicare Part D coverage gap. PLoS Medicine/Public Library of Science 8: e1001075.

52. Li P, McElligott S, Bergquist H, Schwartz JS, Doshi JA (2012) Effect of the Medicare Part D coverage gap on medication use among patients with hypertension and hyperlipidemia. Annals of Internal Medicine 156: 776-784, W-263, W-264, W-265, W-266, W-267, W-268, W-269.

53. Haynes RB, Taylor DW, Sackett DL, Compliance in health care 1979; Baltimore. Johns Hopkins University Press.

54. UK Prospective Diabetes Study (UKPDS) Group (1998) Intensive blood-glucose control with sulphonylureas or insulin compared with conventional treatment and risk of complications in patients with type 2 diabetes. The Lancet 352: 837853.

55. Gilmer TP, O'Connor PJ, Manning WG, Rush WA (1997) The Cost to Health Plans of Poor Glycemic Control. Diabetes Care 20: 1847-1853.

56. Balkrishnan R, Rajagopalan R, Camacho FT, Huston SA, Murray FT, et al. (2003) Predictors of medication adherence and associated health care costs in an older population with type 2 diabetes mellitus: A longitudinal cohort study. Clinical Therapeutics 25: 2958-2971.

57. Vrijens B, Vincze G, Kristanto P, Urquhart J, Burnier M (2008) Adherence to prescribed antihypertensive drug treatments: longitudinal study of electronically compiled dosing histories. BMJ 336: 1114-1117.
58. Hill MN, Miller NH, DeGeest S, on Behalf of the American Society of Hypertension Writing G (2010) ASH Position Paper: Adherence and Persistence With Taking Medication to Control High Blood Pressure. The Journal of Clinical Hypertension 12: 757-764.

59. Cherry SB, Benner JS, Hussein MA, Tang SSK, Nichol MB (2009) The Clinical and Economic Burden of Nonadherence with Antihypertensive and LipidLowering Therapy in Hypertensive Patients. Value in Health 12: 489-497.

60. Ho PRJSMFA, et al. (2006) EFfect of medication nonadherence on hospitalization and mortality among patients with diabetes mellitus. Archives of Internal Medicine 166: 1836-1841.

61. McCombs JS, Nichol MB, Newman CM, Sclar DA (1994) The Costs of Interrupting Antihypertensive Drug Therapy in a Medicaid Population. Medical Care 32: 214-226.

62. Jha Ak Fau - Aubert RE, Aubert Re Fau - Yao J, Yao J Fau - Teagarden JR, Teagarden Jr Fau - Epstein RS, Epstein RS (2012) Greater adherence to diabetes drugs is linked to less hospital use and could save nearly $\$ 5$ billion annually. Health affairs (Project Hope).

63. WorldHealthOrganisation (June 2011) The top 10 causes of death

64. Repetto L, Audisio RA (2006) Elderly patients have become the leading drug consumers: it's high time to properly evaluate new drugs within the real targeted population. Journal of Clinical Oncology 24: e62-e63.

65. Metge C, Black C, Peterson S, Kozyrskyj AL (1999) The population's use of pharmaceuticals. Medical Care 37: JS42-59. 